\title{
Extraction of Antipyretic Properties from Planted AquilariaSubintegra Spp. Dried Leaves
}

\author{
Habsah Alwi, Ku Halim Ku Hamid, Nadira Ikhsan, Suhaiza Hanim Hanipah, and Hanafiah Zainal Abidin
}

\begin{abstract}
Non-steroidal anti-inflammatory drugs (NSAIDs) are widely used to treat fever in human body and veterinary medicine such as drugs, aspirin, ibuprofen, naproxen and paracetamol. NSAIDs are a class of drugs that provides antipyretic effects that is used for fever-reducing agent. Fever is normal condition that is faced by human body when the blood temperature rises and the heat production in the body increasing and cause human body weak, fatigue, and headache, warmth, sweating and feeling cold. However, synthetic drugs have dangerous side effect towards human body if over dosages. Thus, herbal medicine is found out as an alternative way that can be used to treat fever and relief pain. Some researcher found that AquilariaSubintegra Spp. contains antipyretic properties that can reduce fever. The aim for this study is to determine the n-hexane extractionof antipyretic properties from planted AquilarisSubintegra Spp. dried leaves by using conventional oven. The antipyretics properties are obtained in different drying temperature 40,50 and $60^{\circ} \mathrm{C}$. As the drying temperature increase, the retention time will be reduced and the presences of antipyretic properties can be detected.
\end{abstract}

Index Terms-Non-steroidal anti-inflammatory (NSAIDs), AquilariaSubintegra Spp., antipyretic, fever.

\section{INTRODUCTION}

Non-steroidal anti-inflammatory drugs (NSAIDs) are used widely to treat fever as well as for cardiovascular protection in human and veterinary medicine [1], [2]. NSAIDs can be used for treating allergies and reducing pain but it have side effect towards human body which can cause respiratory depression and addiction [2].

Nevertheless, all the synthetic drugs is tend to be declined by consumer since they have dangerous side effect, thus some of the synthetic drugs will be replaced by using the traditional plant or herbal medicine [3]. Nowadays, many researchers were trying to derive medicinal plants into medicine such as steroids, coumarins, flavonoids, polyphenols, alkaloids and terpenes because they have broad range of pharmacological significance including antipyretic, anti-inflammatory and analgesic activities and can reduce the side effects towards human beings [1].

Fever will cause blood temperature rises and causing the increase of heat production in the body [3]. According to [4], antipyretic activity in medicine can reduce the of elevated

Manuscript received on December 20, 2014; revised February 2, 2016. This work was supported by Ministry of Education (MOE), Malaysia for providing the financial support through Research Acculturation Grant Scheme (RAGS), 600-RMI/RAGS 5/3 (55/2012) and Fundamental Research Grant Scheme (FRGS), 600-RMI/FRGS 5/3 (95/2013).

The authors are with the Faculty of Chemical Engineering, Universiti Teknologi MARA, 40450 Shah Alam, Selangor, Malaysia (e-mail : habsahalwi@salam.uitm.edu.my). body temperature. Antipyretic is usually found in acetaminophen with the chemical name of $\mathrm{N}$-acetyl-p-aminophenol [5]. Antipyretic is safe and effective drugs in treating fever for adult and children [6].The planted AquilariaSubintegra Spp. dried leaves is used in this study to find the amount of antipyretic in the leaves. Due to the some research, the demand of AquilariaSubintegra is keep increasing due to the production of traditional medicine [7]. It is widely distributed in many countries such as Malaysia, India, Indonesia, Iran, Singapore, Thailand and many more [8]. Planted AquilariaSubintegra Spp. tree is one of the plants that live widely in tropical rainforest climate. The solvent that can be used for the extraction process is ethanol, hexane, hydrochloric acid, methanol, chloroform or carbon dioxide [9].

Drying is an economical and common preservation technique for herbal medicine [10]. Drying process is done to increase the quality characteristics such as nutritional value and color of the leaves. Besides that, the drying process is also able to change the physical appearance of the leaves like structural, smell and taste [11]. The extraction process using solvents is called solvent extraction whereby the solvent such as methanol, ethanol, chloroform, ethylacetate, hexane, acetone, acetonitrile and dichloromethane were used [12]-[14]. Drying process gave significant impact to theextracted products in which affected the active constituent due to the higher temperature will denatured certain active component [15].

In this study, the n-hexane extraction is used to extract the valuable component from this leaves. The objective for this study is to determine the n-hexane extraction of antipyretic properties from planted AquilariaSubintegra Spp. dried leaves by using conventional oven at different drying temperature and to study the effect of drying temperature and retention factor and retention time.

\section{METHODOLOGY}

\section{A. Materials}

The materials and chemicals used for this research are wild AquilariaSubintegra Spp. leaves, paracetamol and n-hexane

\section{B. Sample Collection}

For this research, $5 \mathrm{~kg}$ of planted AquilariaSubintegra Spp. leaves were collected from the plantation at Selangor, Malaysia in January 2014. The weather of the tropical rainforest climate in Malaysiais is hot and humid every year with the average temperature of $22{ }^{\circ} \mathrm{C}$ and $32{ }^{\circ} \mathrm{C}$ [16]. The plantedleaves collected were washed with distilled water to remove the impurities for the drying process. 


\section{Drying Process}

The leaves were dried in conventional oven (Model:Xuo 58) atthree different temperature of 40,50 and $60^{\circ} \mathrm{C}$ for 24 hours [1], [17]. Then, the leaves will be grinded by using mechanical grinder, Retsch SM 100 to reduce the size to 1 $\mathrm{mm}$ of the leaves in the form of powdered. The leaves were grinded to increase the total surface area for the reaction. After that, the sample will be sieved to achieve the size approximate $1 \mathrm{~mm}$ of the sample [18].

\section{Extraction}

Soxhlet extractor was used to extracts the antipyretic properties. The amount of planted AquilariaSubintegra Spp. leaves powder that has been dry in $40^{\circ} \mathrm{C}$ is weighted to $10 \mathrm{~g}$ and placed in the timble [19]. $200 \mathrm{~mL}$ of $n$-hexane $\left(\mathrm{C}_{6} \mathrm{H}_{14}\right)$ as the co-solvent is placed in the flask of the soxhlet extractor. The boiling point of $n$-hexane is $68^{\circ} \mathrm{C}$. The $n$-hexane is heated until it reached the boiling point and vaporizes to the bypass sidearm. The extraction complete within 3 hours and the process will be repeated for another two different temperatures. The extracts were stored at $4{ }^{\circ} \mathrm{C}$ for the analysis.

$500 \mathrm{mg}$ of Paracetamol tablets were obtained from the pharmacy around Shah Alam, Selangorfor the acetominophen'sstandard. The tablet is grounded into fine powder and suspended in dichloromethane. The suspension were warmed in the water bath at $30^{\circ} \mathrm{C}$ and the suspension is filtered by using filter paper to separate the solid residue and liquid product. The isolated acetominophen were obtained in liquid residue.

\section{E. Analysis Study}

The comparison of the antipyretic activity in the plantedAquilariaSubintegra Spp. leaves wereanalysed. The analysis were done by using High Performance Liquid Chromatography (HPLC) and Thin Layer Chromatography (TLC).

\section{1) High performance liquid chromatography (HPLC)}

Thestandard acetominophen solution was prepared by dissolving $20 \mathrm{mg}$ of isolated paracetamol and $100 \mathrm{~mL}$ of methanol. $40 \mathrm{mg}$ of sulphamethoxazole was dissolved in 100 $\mathrm{mL}$ of methanol as an internal standard. Five different concentration of standard solution; 120, 140, 160, 180 and $200 \mathrm{ppm}$ was prepared. Each of the standards was added with $1 \mathrm{~mL}$ of internal standard of sulphamethoxazole [20]. In addition the mobile phase was prepared by taking $330 \mathrm{~mL}$ of methanol and $660 \mathrm{~mL}$ of water. The calibration curve was obtained from the standard solution.

\section{2) Thin layer chromatography (TLC)}

The paracetamol obtained were dissolved in $3 \mathrm{M}$ of sodium hydroxide solution $(\mathrm{NaOH})$ whereas the caffeine was dissolved in dichloromethane. Then the solution was acidified with $3 \mathrm{M}$ of hydrochloric acid $(\mathrm{HCl})$ to obtain $\mathrm{pH}$ value between 2 to 3 . The precipitation of paracetamol were obtained by filtration.

The TLC plate is marked the strating point with a pencil. Then, the sample is spotted on the TLC plate with a capillary tube. After that, the TLC chamber and iodine as the eluting solvent were prepared. The TLC plate were put inside the TLC chamber containing iodine [21]-[23]. Spot of acetaminophen will be displayed in the TLC plate and visualized under ultraviolet lamp.

\section{RESULTS AND DISCUSSION}

\section{A. Effect of Difference Drying Temperature and Retention Time}

The effect of retention factor was studied by using the thin layer chromatography (TLC) method for three different drying temperatures of leaves which are 40,50 and $60^{\circ} \mathrm{C}$.

Fig. 1 shows the TLC analysis obtained for three different drying temperatures of AquilariaSubintegra Spp. leaves respectively. The spot form in the TLC plate shows the component presence in the solution. The extraction product drying temperature of $40^{\circ} \mathrm{C}$ leaves shows that the level of spot formedwere not the same as the level of spot form for standard solution of isolated paracetamol. However, the extraction product of drying temperature of 50 and $60^{\circ} \mathrm{C}$ shows the same level of spot form for standard solution of isolated paracetamol.

The same level of spot formed in the TLC plate shows the same component presence in the solution. For this research, it can explain that the properties of the paracetamol and extraction of AquilariaSubintegra Spp. leaves contains the same properties that can reduce fever since paracetamol have those properties. It can prove that AquilariaSubintegra Spp. contains antipyretic properties that can reduce fever and pain to the human body since the level of spot is same as paracetamol level.

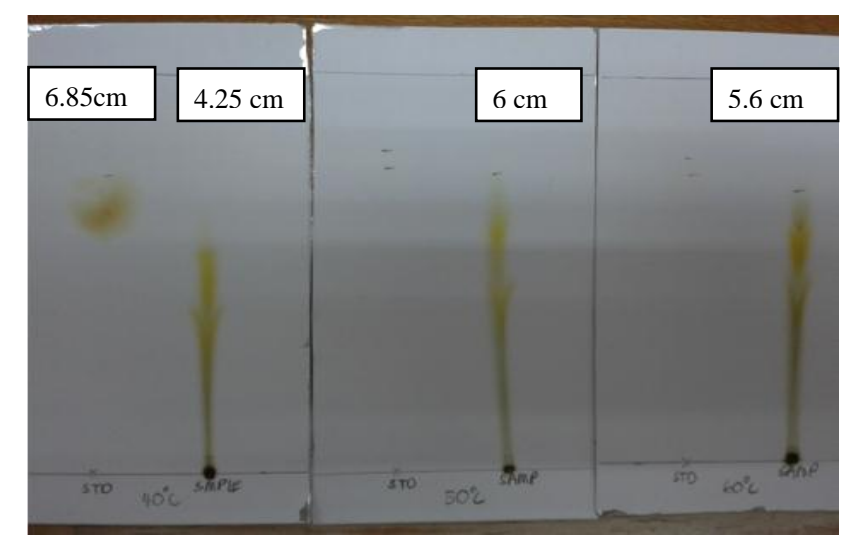

Fig. 1. The TLC analysis of three different drying temperature of Aquilaria Subintegra Spp.leaves.

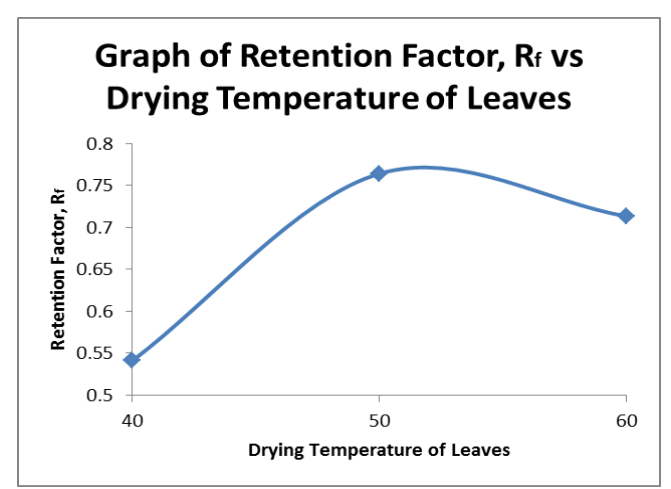

Fig. 2. Effect of drying temperature with retention factor, $R_{f}$

In addition, the retention factor can be determined from this analysis. In the TLC analysis, the retention factor of the component can be calculated. Fig. 2 shows that the graph of retention factor, $R_{f}$ versus drying temperature of leaves, ${ }^{\circ} \mathrm{C}$. The retention factor of drying temperature of 40 and $50^{\circ} \mathrm{C}$ is 
gradually increasing with the retention factor of 0.5414 and 0.7643 respectively. However, the retention factor of the drying temperature of $60{ }^{\circ} \mathrm{C}$ is decreasing with the retention factor of 0.7134 .

The retention factor, $R_{f}$ of drying temperature leaves of 50 and $60^{\circ} \mathrm{C}$ are approximately the same. It shows the identical compound exists. However, the retention factor, $R_{f}$ of drying temperature leaves of $40^{\circ} \mathrm{C}$ has the huge different between the others which shows the different compound. One of the reasonsmay be due to the high moisture content that presence in the leaves sample that not fully evaporates during lower temperature. The distance travel of sample on the TLC plate will be larger if the retention factor, $R_{f}$ of the compound larger. It is occur due to the less polarity of the compound because it interacts less strongly with the polar adsorbent on the TLC plate. Thus, the component of drying temperature leaves of 50 and $60^{\circ} \mathrm{C}$ have the identical compound with the approximate retention factor, $R_{f}$. Therefore, the antipyretic properties exist in the drying temperature of 50 and $60^{\circ} \mathrm{C}$.

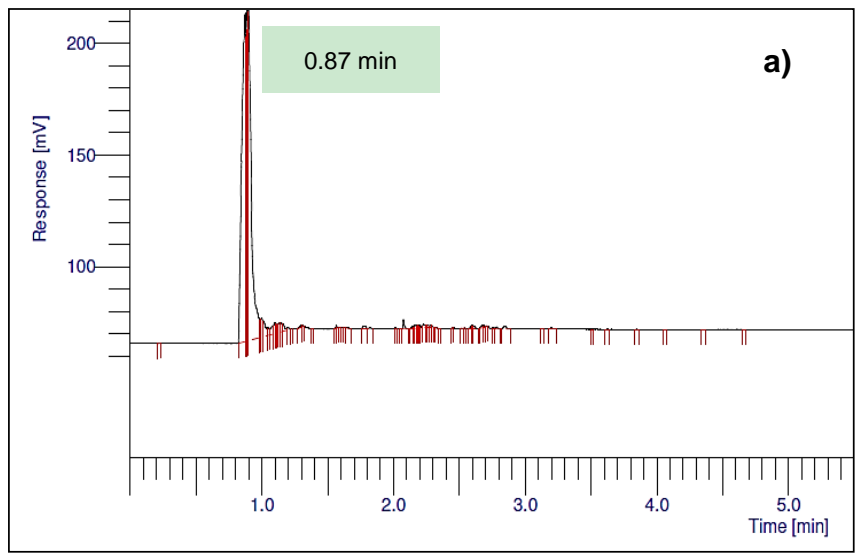

\section{B. Effect of Different Drying Temperature, Retention Time} and Response of the Sample

Fig. 3 shows that the calibration curves of the standard paracetamol solution. Based on the results the ratio integrated area of sulphamethoxazoleand paracetamol were increased as the concentration increased.

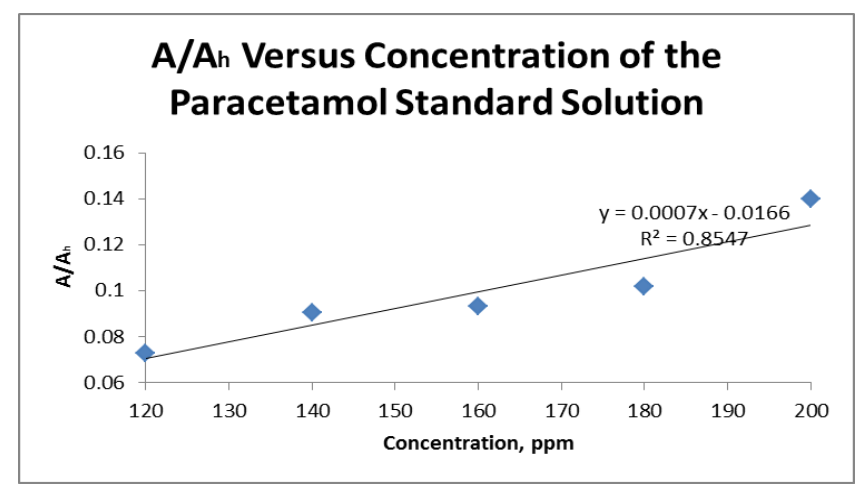

Fig. 3. The calibration curves of the standard paracetamol solution.

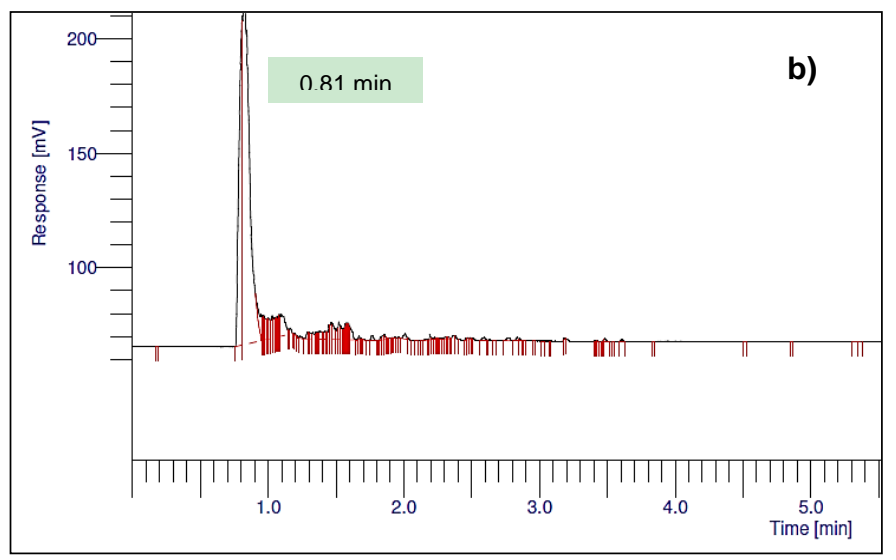

Fig. 4. HPLC peaks of acetominophen of the different drying temperature (a) 40, (b) 50 and (c) $60^{\circ} \mathrm{C}$.

The average retention time for acetaminophen and sulphamethoxazole are 0.896 and 1.02 respectively. This method was performed to determine the amount of the paracetamol to determine the existance of the compound. The $R^{2}$ obtained is 0.8547 whichrepresentthe recovery of paracetamol in the synthetic mixture.

Moreover, the retention time of extraction sample of three different drying temperature of AquilariaSubintegra Spp. was determined by using HPLC. The retention time was identified from the peaks produced in the HPLC analysis at the specific time. Fig. 4 shows the peaks produced of dried leaves at various temperature.

The retention time of the first peak produced at three different drying temperatures should be approximately the same if the same component presence in the sample. The retention time for drying temperature leaves of 50 and $60{ }^{\circ} \mathrm{C}$ is approximately the same which is 0.87 and $0.81 \mathrm{~min}$ respectively. According to [24], the retention time for acetaminophen is $0.80 \mathrm{~min}$. In addition, the retention time for sulphamethoxazole is less than $3.5 \mathrm{~min}$ [25]. However, the retention time for the drying temperature of leaves at $40{ }^{\circ} \mathrm{C}$ shows that the different of the retention time is quite huge which is $1.02 \mathrm{~min}$. This is may be due to the high moisture content of the leaves that will affect the extraction process. The high moisture content, the low of the extraction product will be obtained.
In order to identify the component presence in each of the sample, the average retention time will be approximately the same. The retention time for the standard solution of paracetamol is $0.896 \mathrm{~min}$. In addition, the retention time for the drying temperature of leaves at 50 and $60{ }^{\circ} \mathrm{C}$ is nearly the same which are 0.87 and 0.81 respectively. It shows that the same component presence in the sample. Since paracetamol have the properties which are antipyretic properties that can reduce fever and pain, thus the 50 and $60{ }^{\circ} \mathrm{C}$ of drying temperature of AquilariaSubintegra Spp. leaves are also have the antipyretic properties. According to [1], the higher drying temperature was set, the better extraction thus the easier to detect the presence of antipyretic properties. As the drying temperature higher, the moisture content will be reduced. Thus, the higher drying temperature will enhance the quality of the leaves and it will reduce the retention time.

\section{CONCLUSION}

This research shows that AquilariaSubintegra Spp. leaves contains antipyretic properties that can be used as the natural medicine to treat fever. From this study also shows that the drying temperature of $60{ }^{\circ} \mathrm{C}$ is the best drying temperature in order to identify the antipyretic properties of AquilariaSubintegra Spp. leaves. The less moisture content will help the identification of antipyretic properties in the 
AquilariaSubintegra Spp. leaves. Thus, AquilariaSubintegra Spp. leaves can be used as the medicine to reduce fever.

\section{ACKNOWLEDGMENT}

The author would like to thanks Ministry of Education (MOE), Malaysia for providing the financial support through Research Acculturation Grant Scheme (RAGS), 600-RMI/RAGS 5/3 (55/2012) and Fundamental Research Grant Scheme (FRGS), 600-RMI/FRGS 5/3 (95/2013) for this research and Faculty of Chemical Engineering, UniversitiTeknologi MARA, Shah Alam for the research facilities.

\section{REFERENCES}

[1] S. S. Amol and A. R. Kallangouda, "Anti-inflammantory, analgesic and antipyretic properties of ThespesiapopulneaSoland ex. Correa seed extracts and its fractions in animal models," Journal of Ethnopharmacology, vol. 137, pp. 1504-1509, 2011.

[2] A. S. Yazdi, A. Amiri, G. Rounaghi, and H. E. Hosseini, "Determination of non-steroidal anti-inflammatory drugs in water samples by solid-phase microextraction based sol-gel technique using poly (ethylene glycol) grafted multi-walled carbon nanotubes coated fiber," Analytica Chimica Acta, vol. 720, pp. 134-141, 2012.

[3] T. Sajeesh, K. Arunachalam, and T. Parimelazhagan, "Antioxidant and antipyretic studies on Pothosscandens L. Asian Pacific," Journal of Tropical Medicine, pp. 889-899, 2011.

[4] M. Gupta, U. K. Mazumder, K. R. Sambath, P. Gomathi, Y. Rajeshwar, B. B. Kakoti, and S. V. Tamil, "Anti-inflammatory, analgesic and antipyretic effects of methanol extract from Bauhinia racemosa stem bark in animal models," Journal of Ethnopharmacology, vol. 98, pp. 267-273, 2005.

[5] Thespesiapopulnea. (2013). [Online]. Available: http://en.wikipedia.org/wiki/Thespesia_populnea

[6] E. Rosenbloom, Y. Finkelstein, W. T. Adams, and E. Kozer, "Do antipyretics prevent the recurrence of febrile seizures in children? Asystematic review of randomized controlled trials and meta-analysis,' European Journal of Paediatric Neurology, pp. 1-4, 2013.

[7] M. C. M. Eurlings, B. H. H. Van, and B. Gravendeel, "Polymorphic microsatellites for forensic identification of agarwood (Aquilariscrassna)," Forensic Science International, vol. 197, pp. 30-34, 2010.

[8] K. Premalatha and A. Kalra, "Molecular phylogenetic identification of endophytic fungi isolated from resinous and healthy wood of Aquilariamalaccensis, a red listed and highly exploited medicinal tree," Fungal Ecology, vol. 6, pp. 205-211, 2013.

[9] Y. Liu, J. Shi, and T. A. G. Langrish, "Water-based extraction of pectin from flavedo and albedo of orange peels," Chemical Engineering Journal, vol. 120, pp. 203-209, 2006.

[10] V. Patil, A. K. Chauhan, and R. P. Singh, "Optimization of spray drying process for developing guava powder using response surface methodology," Powder Technology, vol. 253, pp. 230-236, February 2014.

[11] B. Sturm, A. M. N. Vega, and W. C. Hofacker, "Influence of process control strategies on drying kinetics, colour and shrinkage of air dried apples," Applied Thermal Engineering, vol. 62, pp. 455-460, 2014.

[12] Z. Z. Zhu, K. J. Ma, X. Ran, H. Zhang, C. J. Zheng, T. Han, Q. Y. Zhang, and L. P. Qin, "Analgesic, anti-inflammatory and antipyretic activities of the petroleum ether fraction from the ethanol extract of Desmodiumpodocarpum," Journal of Ethnopharmacology, vol. 133, pp. 1126-1131, 2011.

[13] Z. L. Zhang and J. L. Zhou, "Simultaneous determination of various pharmaceutical compounds in water by solid-phase extraction-liquid chromatography-tandem mass spectrometry," Journal of Chromatography A, vol. 1154, pp. 205-213, 2007.

[14] E. J. Akpan, J. E. Okokon, and I. C. Etuk, "Antiplasmodial and antipyretic studies on root extract of Anthocleistadjalonensis against
Plasmodium berghei," Asian Pacific Journal of Tropical Disease, pp. 36-42, 2012

[15] J. Rodriguez, E. C. Melo, and J. Bon, "Optimization of the antioxidant capacity of thyme (Thymus vulgaris L.) extracts: Management of the convection drying process assisted by power ultrasound," Journal of Food Engineering, vol. 119, pp. 793-799, 2013.

[16] World Weather Online. (2013). [Online]. Available: http://www.worldweatheronline.com/Kuala-Lumpur-holiday-guide/K uala-Lumpur/MY.aspx

[17] H. Toğrul, "Suitable drying model for infrared drying of carrot," Journal of Food Engineering, vol. 77, pp. 610-619, 2006.

[18] H. N. Xu, W. N. Huang, and C. H. He, "Modeling for extraction of isoflavones from stem of Puerarialobata (Willd.) Ohwi using n-butanol/water two-phase solvent system," Separation and Purification Technology, vol. 62, pp. 590-595, 2008.

[19] R. A. A. Mothana, M. S. Al-Said, A. J. Al-Rehaily, T. M. Thabet, N. A. Awad, M. Lalk, and U. Lindequist, "Anti-inflammatory, antinociceptive, antipyretic and antioxidant activities and phenolic constituents from LoranthusregularisSteud," Ex Sprague. Food Chemistry, vol. 130, pp. 344-349, 2012.

[20] S. Suzen, C. Akay, S. Tartilmis, R. S. Erdol, A. Onal, and S. Cevheroglu, "Quantitation of acetaminophen in pharmaceutical formulations using high performance liquid chromatography," J. Fac Pharm. Ankara, vol. 27, no. 2, pp. 93-100, 1998.

[21] Experiment 11-Separation and Identification of the Major Components of Common Over-the-Counter Painkilling Drugs. (2013). [Online]. Available: http://www.chem.cuhk.edu.hk/RBS6_Photos/Expt_11.htm

[22] Alvarez M. (2011). Synthetic Drugs Show Deadly Side Effects [Online]. Available: http://www.foxnews.com/health/2011/11/08/synthetic-drugs-show-de adly-side-effects/

[23] K. Williamson, R. Minard, and K. Masters. (2007). Macroscale and Microscale Organic Experiments, $5^{\text {th }}$ edition. Boston: Houghton Mifflin. [Online]. Available: http://depts.gpc.edu/ dunchelb/1152L/TLC.pdf

[24] A. G. Huesgen, "Analysis of Paracetamol and aspirin in pain relievers on the Agilent 1220 Infinity Isocratic LC system with manual injector,' Agilent Technologies Inc.

[25] S. Paulo, "Determination of sulphamethoxazole in pharmaceutical formulations by flow injection system/HPLC with potentiometric detection using polypyrrole electrode," Journal of the Brazilian Chemical Society, vol. 22, 2011.

Habsah Alwi was born in Johor, Malaysia. She received her first degree B.Eng.(Hons) Chemical Engineering from Universiti Teknologi Malaysia (UTM) in Skudai, Johor. She obtained her second degree, M.Sc Chemical Enginering from Universiti Teknologi MARA (UiTM), Shah Alam, Malaysia

Ku Halim Ku Hamid was born in Kedah, Malaysia. Currently he is a professor in Faculty of Chemical Engineering, Universiti Teknologi MARA (UiTM) Shah Alam, Malaysia.

Nadira Ikhsan was born in Malaysia and received her degree B. Eng (Hons) Chemical Engineering from Universiti Teknologi MARA (UiTM) Shah Alam, Malaysia

Suhaiza Hanim Hanipah was born in Malaysia and received her firs degree B. Eng (Hons) Chemical Engineering from Universiti Teknologi MARA (UiTM) Shah Alam, Malaysia. Her Master degree was from one of university from New Zealand

Nurul Asyikin Md Zaki currently is a lecturer in Faculty of Chemical Engineering, Universiti Teknologi MARA, (UiTM) Shah Alam, Malaysia

Nurhaslina Che Radzi currently is a senior lecturer in Faculty of Chemica Engineering, Universiti Teknologi MARA, (UiTM) Shah Alam, Malaysia 